\title{
On the Legacy of G. Pólya: Some new (old) aspects of mathematical problem solving and relations to teaching
}

\author{
BERND ZIMMERMANN
}

Abstract. In this article are given some new aspects of mathematical problem solving. A framework is presented by three main resources: (1) Pólya's studies about mathematical heuristics are augmented by information drawn from a study of the history of mathematical problem solving. (2) Connections are presented between mathematical problem solving and mathematical beliefs. (3) Experience with a special program for mathematical talented students is sketched. On this background a new textbook-series has been developed and some teaching examples are taken from this context. An outlook is given on some new research on teaching of problem solving, including possible relations to modern brain research.

Key words and phrases: problem solving, heuristics, problem solving processes, understanding and teaching of mathematical problem solving, history of mathematical problem solving.

ZDM Subject Classification: C30, D50.

\section{Introduction}

Problem solving has been a major focus in the international discussion of mathematics instruction since several decades. During the last century this discussion was mainly stimulated and proliferated by the well known extraordinary work of G. Pólya (cf. Pólya [24], [22], [23], some recent summaries with other examples can be found in Zimmermann [36], [39]). 
Nevertheless there seem to be very often obstacles for an effective implementation of Pólya's and other author's ideas about this domain into practical school life. This impression might be reinforced by results from recent international studies like TIMSS and PISA especially with respect to Germany (cf. Baumert et al. [3]).

In spite of the fact that there are also discussions about the quality and validity of problems resp. tasks from TIMSS or PISA-Tests (cf. Kießwetter [20]) it seems to be useful to try to come to a better understanding of mathematical problem solving processes and its different boundary conditions.

Many studies have been already carried out to learn more about mathematical problem solving processes ${ }^{1}$. We got some more information with respect to mathematical problem solving from the following domains, which can be only sketched here because of limits of space:

- Problem solving and history of mathematics,

- problem solving and mathematical beliefs,

- problem solving and experience with a project for talented pupils.

In the following section we present some teaching examples, which refer to these aspects. Finally we report among other things about a PhD-study - taking mathematics instruction as problem solving in a complex domain and using multimedia - which can give some better understanding of difficulties of mathematics teacher students with teaching of mathematical problem solving. We conclude with some remarks about results from modern brain research and possible relation to mathematical problem solving.

\section{Some additional aspects for the study of mathematical problem solving}

\section{History of Mathematics}

Studies of the history of mathematics with educational intention have been carried out nearly as long as mathematics exists. This can be seen, e.g., by presentations of nice historic examples ${ }^{2}$, fundamental ideas drawn from history

${ }^{1}$ Cf. for example Silver [26] and the proceedings of the PME (International Group for the Psychology of Mathematics Education).

${ }^{2}$ You can find such gems not only in the well known books of Pólya but also in many other books (Cofman [5], [6]; Inter-IREM [16]). 
of mathematics (cf. Stowasser [28]), anecdotes as well as teaching courses guided by the "historic-genetic principle" (cf. Toeplitz [30]).

Pólya's inquiry of heuristic strategies includes reference to history of mathematics as well. He presented excellent examples and some very interesting theoretical contributions to the nature of plausible reasoning. But he did not study in a systematic way the importance and the rank of specific heuristic methods, as it might be seen from their respective development, their effect and their productivity (to generate new mathematics) within 5000 years of history of mathematics. So we carried out a study of the history of mathematics as a long term study of thought processes and methods which lead again and again to new mathematics.

Because of limits of space and time we can only present some results from more comprehensive studies (cf. Zimmermann [33], [34]). The following heuristics are of overwhelming importance in that sense ("invariants" with respect to productivity); the list is neither comprehensive nor are the concepts disjoint (esp. not to those used by Pólya!):

$>$ informal methods,

$>$ successive approximation (including the method of false position up to "regula falsi" and modern iteration-methods),

$>$ analytical method (working backwards),

$>$ analogy,

$>$ changing the mode of representation (cf. Wagner/Zimmermann [31]),

$>$ atomistic methods (working with "indivisibles"),

$>$ variation and generalization,

$>$ abstraction (chunking, formation of super signs (cf. Wagner/Zimmermann [31])).

Some heuristics, which proved to be very important during the last 5000 years

Another important outcome of these studies made clear that heuristic strategies developed normally first implicitly over a long range of time. For example the classical method of analysis (working backwards) has been used implicitly (that means: without intention and not consciously) in solving quadratic equations (cf. Hørup [15], see also next chapter) already more than two thousand years before Pappos from Alexandria discussed explicitly its use (cf. Jones [14]). This fact might give some hints for the productive teaching of heuristics, which 
were presented already by Leibniz (cf. Gerhardt [11, p. 523]). He compared the learning of mathematical problem solving with the learning of a language by a young child. Before there is not enough own experience - he sad - there is not enough material to be structured and reflected about. Therefore problem solving should be learned first by solving a lot of problems before starting to think about methods/heuristics (metacognitive activities) which might help to improve additionally problem solving ability.

We tried to broaden the view on history of mathematics from cognitive processes and heuristics to further activities and motives which might have stimulated the creation of mathematics and its reasonable use (cf. Zimmermann [40]). We came to at least eight activities or classes of activities - including methods of heuristics - which seem to us fundamental in the aforementioned sense. They are connected with some other fundamental ideas:

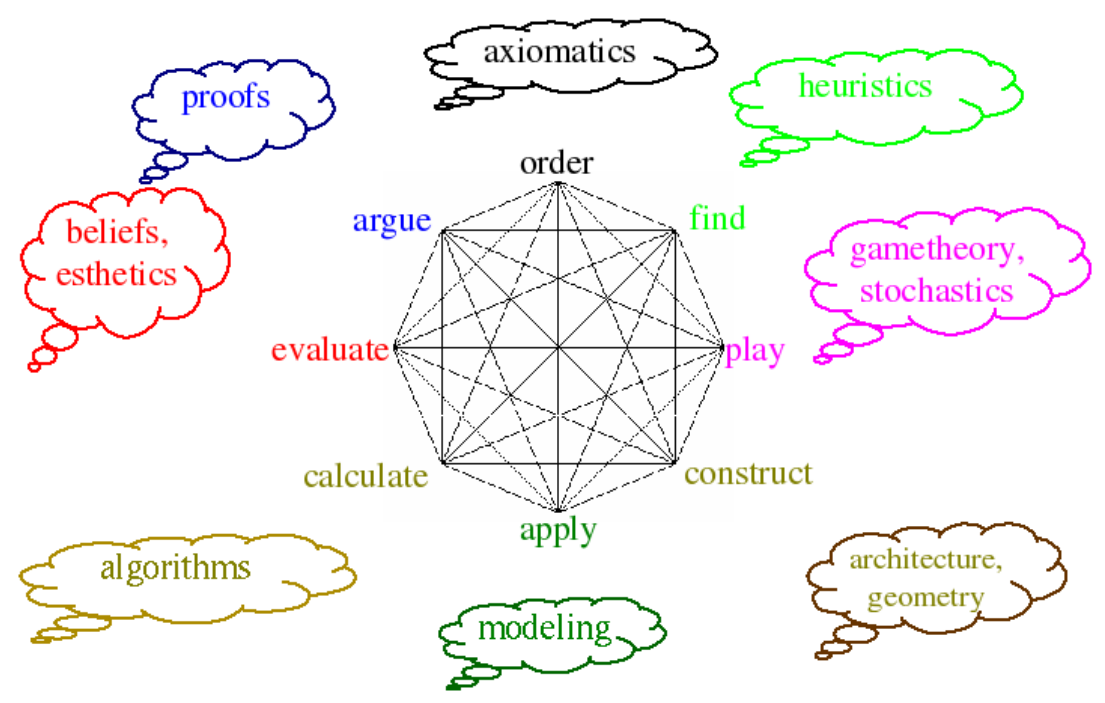

- Calculate, apply and construct are very old and also basic activities at school and in every-day-life. Therefore they are at the basis of the diagram.

- Prove, order (systematic, may be even axiomatic) and find are higher order and more sophisticated activities. Therefore they are placed at the top.

- "Find" is of course related to heuristics, on which we had already a closer look. 
- For example, modern probability theory as well as game and graph theory would not have been invented, if games, recreational mathematics and playing with mathematics would not have been of major interest during history of mathematics. It is very important not only for children but also for grown up mathematicians to play with the subject. The importance of playing and - of course - a stimulating appropriate environment in this direction cannot be exaggerated.

- "Evaluate" is another important activity, which is related to religious or aesthetic systems of values and which is sense making and goal directing in many situation of life (it has been so also in ancient life). Of course, all these activities are connected and interwoven in many ways. The picture tries to represent this, too. Furthermore it might give some orientation for the selection of appropriate learning environments for teaching of mathematics.

\section{Mathematical beliefs}

In an empirical study (cf. Zimmermann [34], [37]) we could see, that beliefs of analyzed teachers as well as of pupils were more dominated by routine techniques or some "Bourbakism" than by ideas of problem solving. This corresponds to outcomes of TIMSS as well as of PISA in Germany. But we could also find considerable individual differences between the beliefs of the teachers (different clusters of belief profiles).

Looking on the history of mathematics and on different regions one could find also different patterns of mathematical beliefs with respect to the aforementioned eight key-activities (cf. Zimmermann [38]).

Experience from a project with mathematically talented pupils

A project to identify and foster mathematically talented pupils hasd been carried out in Hamburg and surrounding counties since 1982. The main idea of this project is to let pupils work in open ended problem fields with a more or less well defined starting point and many "degrees of freedom" such that the pupils can be stimulated to develop or transform the initial situation in many forms corresponding to their motivation and their creative potential. Pupils who are 
interested in joining this program have to pass two tests ${ }^{3}$ at the end of grade 6 . If they are accepted they normally meet two times a month on Saturday morning for three years (grade 7 to 9) at the University of Hamburg. They can also continue and join a more advanced program (many pupils do so).

The main generator of the mathematical ideas is Karl Kießwetter. He developed material for more than 100 sessions $^{4}$.

The author of this article was strongly encouraged especially by experience with problems from this project in normal classes (esp. in classes with lower achievers $^{5}$ ) to develop with several other teachers a textbook-series, which refers to many ideas of this project and the aforementioned ones. The following examples are taken from this context.

\section{Teaching examples}

Example 1. Implicit use of several heuristics in problem-fields We present here an example where tasks and problems are to be solved with increasing difficulty. Heuristics are implicitly involved in possible solution and extension processes ${ }^{6}$.

a) Solve the following systems of equations:

$$
\begin{aligned}
& \text { I) } \quad x+2 y=1 \\
& 2 x+2 y=1 \\
& \text { II) } \quad x+2 y+3 z=1 \\
& 2 x+2 y+3 z=1 \\
& 3 x+3 y+3 z=1 \\
& \text { III) } \quad x+2 y+3 z+4 u=1 \\
& \text { IV) } x+2 y+3 z+4 u+5 v=1 \\
& 2 x+2 y+3 z+4 u=1 \\
& 2 x+2 y+3 z+4 u+5 v=1 \\
& 3 x+3 y+3 z+4 u=1 \\
& 3 x+3 y+3 z+4 u+5 v=1 \\
& 4 x+4 y+4 z+4 u=1 \\
& 4 x+4 y+4 z+4 u+5 v=1 \\
& 5 x+5 y+5 z+5 u+5 v=1
\end{aligned}
$$

${ }^{3}$ A German version of the American SAT and the "Hamburg Test for mathematical Creativity" (HTMB=Hamburger Test für mathematische Begabung). This program was run also in the Center for the Talented Youth (CTY) at the Johns Hopkins University, where there exist good relations and cooperation already for many years. Cf. the contribution of Durden [8].

${ }^{4}$ The main philosophy of this project, some examples and some ideas of the test (HTMB) developed by Kießwetter can be seen for example in Wagner/Zimmermann [31] or Zimmermann [32]. Most material has been written in German and can be received by Kießwetter (kakiahr@aol.com).

${ }^{5}$ German "Haupschule".

${ }^{6}$ It is taken from MatheNetz Vol. 9 (pupils of grade 9, approx. 15 years old), Chapter 1 about linear systems of equations, exercise 16, p. 48. 
b) Find the solution of "the corresponding" general system of linear equations with $n$ variables and $\mathrm{n}$ equations. You might use a computer algebra system for conjecturing. You should give a proof for your conjecture.

c) Put into the last column instead of $n$ times the number 1 (at the right side of $=$ ) the sequence $1 ; 2 ; 3 ; \ldots n$ (respectively: $n ;(n-1) ;(n-2) ; \ldots 3 ; 2 ; 1$; than later on $n$ times $n$, later on $n$ times the constant number $a$ ). What solution do you get now? Give reasons.

d) Invent yourself such systems of linear equations with patterns, which have simple solutions. Your ideas might be stimulated by properties of "figured numbers"!

e) Think about patterns for systems of linear equations not only with respect to the coefficients.

f) Now find to a given sequence of solutions possible systems of equations with patterns. For example: $x=1 ;(x=1$ and $y=2) ;(x=1$ and $y=2$ and $z=3) ;(x=1$ and $y=2$ and $z=3$ and $u=4)$.

Remark. This problem-field was constructed by using patterns from figured numbers to put structures on the coefficient matrix of a system of linear equations (SLE). Think for example of the visualization or the relation between the sum of odd numbers and square numbers:

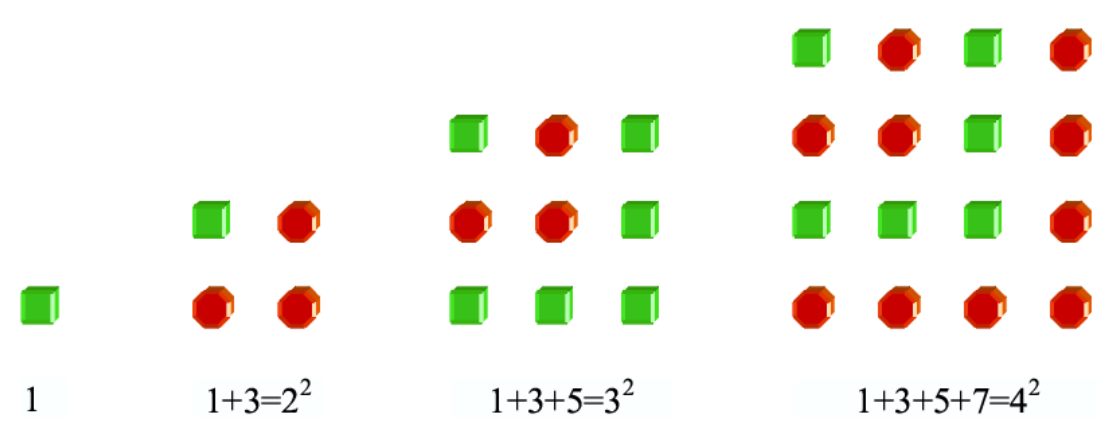

The difficulty and/or the degree of openness are increased step by step.

Part a) should give to every pupil the opportunity to find at least a solution of the most simple system. Proceeding step by step to the more complex systems at the same time possible conjectures might be generated for a solution of the general system. 
Part b) should give to the pupils the opportunity to get some more praxis in conjecturing (with or without CAS!) and arguing.

In part c) a first variation of the initial problem is given.

In d) it is more up to the pupils to be more creative. Depending on his or her experience he or she might check other patterns of figured numbers. One could use for example the triangular numbers concerning shape and also content. You could supplement zeros in such a way that you get a scheme of numbers which one can take as coefficient matrix for a SLE. In similar way the Pascal triangle, the harmonic triangle or the triangle of Farey-fractions might be used (cf. MatheNetz Vol. 7, p. 153). Again conjecturing might be supported by critical use of CAS.

Part e) was constructed as a "reverse problem" in the sense of Piaget, referring to his "operatoric principle". Here is a broad area where pupils can play, construct and discover many things. Of course, this is an internal mathematical problem and no modeling problem. But such problems can be discussed and extended normally better step by step than real applied problems. In this way they can help to motivate pupils more often. Furthermore they can be more appropriate to foster heuristic thinking and creativity.

Example 2. Implicit use of "dominant" heuristics: Changing of the mode of representation and the analytical method (working backwards) The solution of quadratic equations is one of the standard topics in normal mathematics teaching. First testimonies for solution methods of today we can find already on old Babylonian cuneiform plates (cf. Hørup [15, p. 13]):

a) "The surface and my confrontation I have accumulated: 0;45 is it.

b) 1 , the projection, you posit.

c) The moiety of 1 you break,

d) $0 ; 30$ and 0;30 you make hold.

e) $0 ; 15$ to $0 ; 45$ you append: by 1,1 is the equalside.

f) $0 ; 30$, which you have made hold, in the side of 1 your tear out: $0 ; 30$ the confrontation."

Comments:

The writing $0 ; 45(0 ; 15$ and $0 ; 30)$ is a representation of the fraction $3 / 4$ in the sexagesimalsystem: $0 ; 45=45 / 60=3 / 4(0 ; 15=45 / 60=3 / 4 ; 0 ; 30=1 / 2)$. 
Referring to Hørup we give the following (geometric) interpretation:

a) "The surface and my confrontation I have accumulated: 0; 45 is it."

The sum of the area of a square made of sticks and the length of such stick equals $4 / 4$. So this problem can be represented in modern terms by $x^{2}+x=3 / 4$. This is a situation still forbidden for Viète more than three thousand years later, because "inhomogeneous" magnitudes as areas and lengths were not aloud to be added together! Furthermore the sticks of equal unknown length seem to be handled as if their length was already known. So one can think here of "working backwards" implicitly".

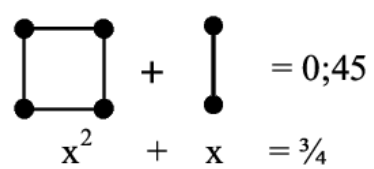

b) " 1 , the projection, you posit."

This is very tricky, because in this way one can interpret that the (unknown) length of the stick was transformed into an area of the same measure by multiplying with the length 1 of the unit.

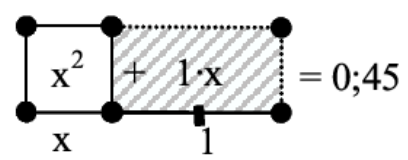

c) "The moiety of 1 you break, 0;30 and 0;30 you make hold."

The stick of length 1 is broken into two parts of length $1 / 2$. The ends are put together, forming a square of area $1 / 2 \cdot 1 / 2=1 / 4$.

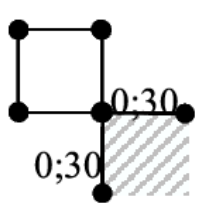

${ }^{7}$ Of course, every solution process of a modern equation can be seen in this way! Therefore "algebra" and "analysis" have been often used as synonyms at Descartes time. 
d) "0; 15 to 0; 45 you append: by 1, 1 is the equalside."

This square with area $1 / 4$ adds up with the area of the grey "angle" $3 / 4$ to a total area of 1 . The corresponding quadrilateral is equilateral with side length 1. Obviously we have here the literal process which we call today "quadratic completion" nearly four thousand years ago!

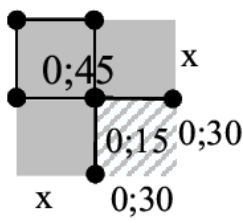

e) "0;30, which you have made hold, in the side of 1 your tear out: 0; 30 the confrontation."

As $x+1 / 2=1$ is also true, we have to subtract $1 / 2$ from 1 and get so $1 / 2$ for the length of the sticks, you have put together.

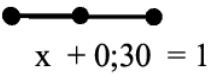

What kind of chances and stimuli this material might give to mathematics instruction? Here are some suggestions:

- Of course one might give the "original text" 8 to (teacher-) students with more or less comments and let them find possible interpretations, let them compare with the interpretation just given and let them discuss this.

- Normal pupils of grade 8 can be given the following (initial) problem (cf. MatheNetz Vol. 8, E3, p. 99):

There is a square of unknown side length $x$. Place on one of its sides a rectangle of breadth $x$ and length 1 . The total area is $3 / 4$.

If necessary and depending on the amount of freedom you want to give to your pupils, you might (let them) add drawings similar to those in b). Furthermore you might supplement even the main idea of the "Babylonian" method (separate the rectangle in two congruent parts and move them in such a way, that you can complete the figure into a square as shown above). Then you might pose the following questions:

${ }^{8}$ Hørup's translation a)-f). 
i) How large is $x$ ?

ii) Now the total area should be $33 / 4$ (and not $3 / 4$ ). What is $x$ now?

iii) Determine $x$, if the supplemented rectangle has a length of 2 and the total area is 3 .

iv) Invent similar problems.

v) Try to reverse the aforementioned process: Given a solution, look for fitting problems. Given a square with given area, which is dissected into two squares (one with given area) and two rectangles. Try to rearrange the "unknown" square and the two "partly" unknown rectangles in such a way that you receive only one rectangle of given area. Formulate an appropriate problem.

Here you have not only the possibility for implicit training of working backwards, but also for changing the mode of representation. There are many possibilities to move back and forth between algebraic and geometric representation of quadratic equations. Of course discussing zeros of graphs of quadratic functions might lead to another well known representation.

Example 3. Implicit use of "dominant" heuristic: working backwards and perfect numbers

A perfect number is a natural number $n$ which equals the sum of its proper divisors (all the numbers which divide $n$ except $n$ itself). For example 6 is perfect, because all proper divisors of 6 are 1; 2 und 3 and $1+2+3=6$.

There is a theorem of Euclid, which makes a statement, that natural numbers of a specific structure are perfect (cf. Heath [12, vol. 2], Euclid [Prop. 36, p. 421]). How did Euclid come to this statement? This question might be posed by Ibn al Haytham, who has written a treaty about the method of analysis and synthesis more than 1000 years ago (cf. Jaouiche [17]) and took the "analysis" of perfect numbers as an example to demonstrate the power of this method ${ }^{9}$.

It can be given to students in the following form:

Given an(y) even perfect number. What structure might it have?

Ibn al Haytham started - as Euclid did in his proof - with the number 496 and "analyzed" its structure. So one could offer this number also to students:

${ }^{9}$ It is still under discussion whether he proved 800 years before Euler the conversion of the theorem of Euclid (Hogendijk [14] and Rashed [24]). 
Listing of all proper divisors, addition, using the formulae for geometric series and some transformation can lead to

$$
\begin{aligned}
496 & =1+2+2^{2}+2^{3}+2^{4}+31+62+124+248 \text { where } 31 \text { is a prime number } \\
& =\left(2^{5}-1\right)+31\left(1+2+2^{2}+2^{3}\right)=\left(2^{5}-1\right) \cdot\left(1+2^{4}-1\right) \\
& =\left(2^{5}-1\right) 2^{4} .
\end{aligned}
$$

Such considerations might yield the conjecture:

If a number $m$ has the form $m=\left(2^{n+1}-1\right) \cdot 2^{n}$ and $2^{n+1}-1$ is prime then $\mathrm{m}$ is perfect (prop. 36 of Euclid in modern notation).

Example 4. Implicit use of "dominant" heuristics: analogy and atomistic methods (circle and sphere) (cf. MatheNetz Vol. 10, 2002, Chapter 4).

Archimedes wrote in his "Measuring the Circle" (Archimedes [1, p. 369]):

The area of a circle equals the area of a rectangular triangle, where one side equals the radius and the other the circumference of the circle.

We write today: $A_{0}=\frac{1}{2} U \cdot r$

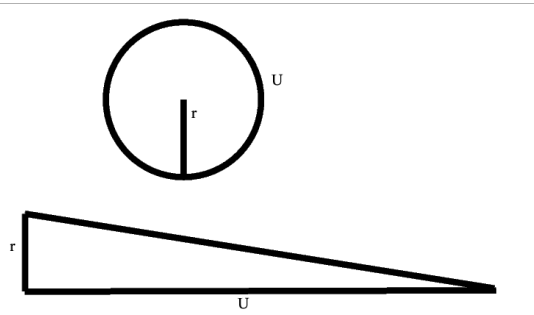

He proved this by double contraposition.

Possible problems/question to your students:

To measure the area of a circle ${ }^{10}$, try to transform a circle into a polygon with the same area.

When Kepler red the text of Archimedes nearly two thousand years later, he could not understand, in which way Archimedes might have come from the circle to such rectangular triangle.

Possible question to your students (after presenting this theorem of Archimedes to them):

Can you guess, in which way Archimedes might have come to his theorem?

\footnotetext{
${ }^{10}$ Without presenting any figure as on this page!
} 
Kepler thought as follows (cf. Kepler in Struik [29, p. 194]):

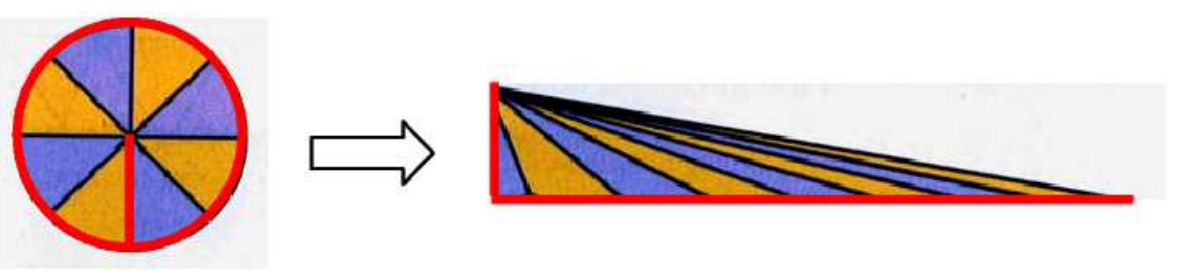

We dissect the circle in many small congruent isosceles. We make a "cut" along one radius, take the circumference like a wire and stretch it straight. Then we get a rectangular triangle, in which we have the same number of small triangles with different shape, but the same basis and the same altitude. Therefore the area of the rectangular triangle must be the same as the area of the circle.

Nearly the same idea the author could hear once from a pupil in one of his classes.

The next question to your students might be the following:

Can you use this idea to get the area of a circle to find the volume of a sphere?

Possible ideas: Instead of many congruent isosceles we take many congruent pyramids with their bottom made from equilateral triangles and their peak in the
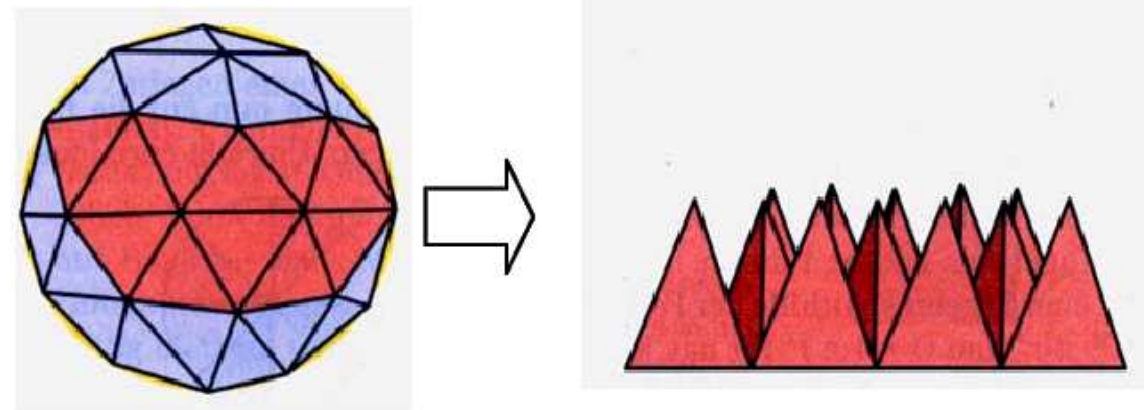

center of the sphere. Then we try to "cut" and "stretch" again. Finally we can try to take the peaks of all pyramids to unify them into one single pyramid, which bottom is the surface of the sphere and which altitude is the radius of the sphere. But: Is this always possible? Anyway: The volume of such small pyramid might be approximated by $V_{p} \approx \frac{1}{3} \nabla A_{\text {sphere }} \cdot r$. If the bottom area is "small enough", the whole volume of the sphere must "tend to" $V_{\text {sphere }}=\sum \frac{1}{3} \nabla A_{\text {sphere }} \cdot r=\frac{1}{3} A_{\text {sphere }} \cdot r$. 
In this way we come at least to a conjecture for the volume of a sphere. One can summarize these ideas and relations in the following diagram:

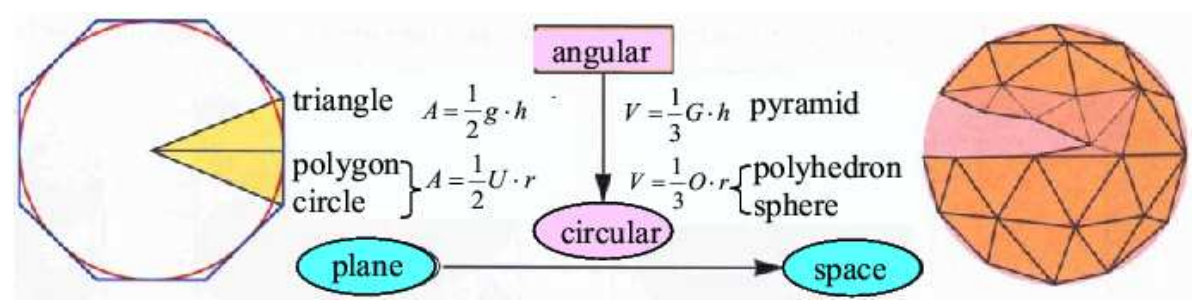

If one has a closer look at the coefficients of the formulae, one might conjecture, that they are related to the respective dimension. So some students might be stimulated to go on to search for formulae for spheres in higher dimensions.

Example 5. Finally: Reflection on heuristics - step by step ${ }^{11}$

Goal of the chapter:

You know the rule that only a lot of practice makes perfect. This holds also for mathematical problem solving. But there are possibilities to accelerate your speed of learning towards a real championship in problem solving considerably. This possibility includes the observation of persons when solving mathematical problems. If you become conscious especially about successful approaches and methods you can very often improve your problem solving ability.

It is especially important to observe yourself, to look on your own thinking activities like a person standing outside of you. The major advantage is that you are especially well informed about your own problem solving activities.

We invite you now to follow the presented steps upwards. How far will you come?

We start with a problem which you might have tackled already. There are many ways to solve it.

${ }^{11}$ This is an excerpt of Chapter 8, MatheNetz Vol. 9, 2001. 


\section{Problem $1^{12}$ :}

You want to invite 10 guests to your birthday party and want to buy 10 cakes. You have 21 Euro. The bakery has two different sorts: one sort costs 2 Euro for one piece, you have to pay 2.30 Euro for a slightly more delicious one. You want to buy as many of the delicious cakes as possible. How many of the more delicious cakes can you buy?

\section{Step of thinking about thinking}

a) Solve the problem and write down your ways to a solution.

b) Compare your ways to solutions. Explain your solution to your classmate. Can you find differences? For example: Is a solution shorter, better, more "beautiful", more "mathematical" than another one? Give reasons for your judgment.

c) Try to find other ways of solution and write them down.

Only until you coped intensively with part a) to c) you should read the following text.

Here we present ways of solution of other pupils.

Ways of solution from other pupils:

AnNABELle wants to buy 10 more delicious cakes. She would have to pay 23 Euro. So she is short of 2 Euro. Therefore she takes one piece of this cake less. But there would be only 30 Cent left for a cheaper cake. So she is lacking still 1.70 Euro. Therefore she has to consider much less of the delicious cakes. So she makes a test with 5 pieces of the better cake. Then she would require 11.50 Euro. Consequently there would be a rest of 9.50 Euro. But for this money she could buy only 4 pieces of the cheaper cake. Now she is lacking only 50 Cent for the 5 th cake of this type. Step by step she continues in this way until it turns out that she has sufficient money for at most three better cakes and totally 10 cakes: She has to pay 6.90 Euro for three more delicious cakes. From the rest of 14.10 Euro she can buy still 7 cheaper cakes.

\footnotetext{
${ }^{12}$ This refers to a problem of the TIMSSVideo-Study from a Japanese class grade 8 .
} 
Her procedure can be written down systematically in the following way:

\begin{tabular}{|c|c|c|c|c|c|c|}
\hline \multicolumn{2}{|c|}{ Deli. cake (2.30 EUR) } & \multicolumn{2}{|c|}{ cheap cake ( 2 EUR) } & \multicolumn{3}{|c|}{ To be paid (in EURO) } \\
\hline \# of cakes & price & \# of cakes & price & total & not more than $21 € ?$ & Deficit \\
\hline 10 & 23 & 0 & 0 & 23 & no & 2 \\
\hline 9 & 20.70 & 1 & 2 & 22.70 & no & 1.70 \\
\hline$\cdots$ & & . & $\cdots$ & $\cdots$ & $\cdots$ & $\cdots$ \\
\hline 5 & 11.50 & 5 & 10 & 21.50 & no & 0.50 \\
\hline 4 & 9.20 & 6 & 12 & 21.20 & no & 0.20 \\
\hline 3 & 6.90 & 7 & 14 & 20.90 & yes! & 0.10 plus! \\
\hline
\end{tabular}

BERTI starts with the cheaper ones: He buys 10 cakes of this type. There will be a rest of one Euro. If he buys 9 cheaper cakes and one more expensive cake than there will be a rest of $21-(9 * 2+2.3)=0.70 €$. In case of 8 cheaper and two better cakes he has left $21-(8 * 2+2 * 2.3)=0.40 €$. Finally he recognized that he can afford three better cakes when buying 7 cheaper cakes, as $21-(7 * 2+3 * 2.3)=0,10 €$, but in case of four more delicious cakes and six cheaper cakes he would run short already of 20 Cent.

Clara proceeds similar to Berti and wants to buy first ten cheaper cakes. She says to herself: "Then I would still have one Euro. But if I would exchange a better cake for a cheaper cake, then I would have to pay 30 Cent more. These would fit at most three times into one Euro; four times would be already more than one Euro. Therefore I may exchange from 10 cheaper cakes still three pieces for three more expensive ones!"

DAVID has especially a lot of fun with mathematics, if he can work with formulae. Therefore he denotes the number of more expensive cakes he can buy with $x$, calculates the amount of money he has to pay for $x$ cakes of this type and $(10-x)$ cheaper cakes. Finally he takes into account that he cannot spend more than $21 €$. He is proud to come in this way to the following inequality:

$x \cdot 2.30+(10-x) \cdot 2 \leq 21$, where $\mathrm{x}$ should be a natural number as large as possible. David carries out equivalent transformations and finally he gets $x \cdot 0.30 \leq 1$ which leads him to the solution $x=3$. 


\section{Step of thinking about thinking}

a) Is your way of solution at least partly the same or similar to ways of solutions sketched above? - If yes: In which part?

b) Which way of solution you know now is (I) most beautiful, (II) could be normally found first, is (III) the most "mathematical way"? Give arguments for your judgment!

c) Which kind of other problems can also be solved by solution methods applied by Annabelle and Berti (systematic trial and error), Clara (thinking in exchange activities) or David (transform situations into formulae and calculate with them)?..."

We give a rough sketch of the further steps of reflection in the textbook MatheNetz 9:

3. A second problem is presented (isoperimetric problem for a rectangle) and is to be solved. The pupils should discuss also in this case their solutions.

4. Then six other pupils' solutions are presented. These solutions should be compared with the own solution and should be evaluated.

5. Finally important heuristics are highlighted in these pupils' solutions (cf. part two). We refer only to the first problem discussed here in more detail: For example Annabel and Berti get a solution by reasonable guessing. Clara's transfer activities, where she concentrates on the difference of prices of the different cakes, can be taken as an informal method. In this way a solution can be received very often more quickly than by reasonable guessing. David solved the problem by using an inequality. When doing so he changed the word problem into a formal (algebraic) one, which corresponds to a change in the mode of representation. When solving the inequality he worked also backwards. He proceeded in an analogous way as in the case of solving an equation. 


\section{Outlook on latest and future research}

We come finally to some very new research which might be useful for understanding, learning and teaching of mathematical problem solving.

Heinrich [13] analyzed very carefully special moments of changes in the problem solving processes of small groups. His results might be of major importance and might help to improve teaching.

Mainly on the basis of the work of Dörner et al. (Frensch/Funke [9]) on "Complex Problem Solving" and Kießwetter [19], Fritzlar [10] developed a complex computer scenario to analyze teacher students' sensitivity for the complexity of problem oriented mathematics instruction. This instrument might help to come to a deeper understanding especially of beginning teachers' difficulties in teaching (open ended) mathematical problem solving. Furthermore, it might help as a training instrument to improve teacher students' ability to cope with complex teaching situation (additionally to classroom praxis, which remains, of course, to be the most important factor in teacher training).

Latest results from brain research support the impression, that a fluent change of modes of representation (especially using the visual mode) seem to be related to mathematically talented pupils (cf. Seidel [25]).

Other new results from brain research seem to demonstrate that in the development of the brain normally there is a preference of "doing" (procedural knowledge) with respect to "understanding" (conceptual knowledge) ${ }^{13}$. This result can be seen in relation to the experience from history, that heuristics occurred normally first implicitly before there might be reflection on them ${ }^{14}$. So there are even more good reasons to think very carefully about possibilities and timing of explicit heuristic training and metacognition (cf. also Bauersfeld [2]). More results from brain research might be of increasing interest for mathematics instruction. But in spite of the tremendous progress in the technical facilities to analyze the brain one has to be always aware of possible problems of interpretation of "observed" data.

\footnotetext{
${ }^{13}$ See for example Spitzer [27], Chapter 4.

${ }^{14}$ See second section.
} 


\section{References}

[1] Archimedes, Werke: im Anh.: Kreismessung, übers. von F. Rudio; Des Archimedes Methodenlehre von den mechanischen Lehrsätzen, übers. von J. L. Heiberg und kommentiert von H. G. Zeuthen/ Archimedes. Übersetzt und mit Anmerkungen versehen von A. Czwalina. Sonderausg. 4. unveränd. reprograf. Nachdruck, Wissenschaftliche Buchgesellschaft, Darmstadt, 1983.

[2] H. Bauersfeld, Fundamental Theories for Elementary Mathematics Education, In: de Lange, J.; Keitel, C.; Huntley, I.; Niss, M.: Innovations in Maths Education by Modelling and Applications, Ellis Horwood, New York, London, Toronto, Sydney, Tokyo, Singapore, 1993.

[3] Jürgen Baumert, Eckhard Klieme, Michael Neubrand, Manfred Prenzel,Ulrich Schiefele, Wolfgang Schneider, Petra Stanat, Klaus-Jürgen Tillmann and Manfred Weiß (Hrsg.), PISA 2000: Basiskompetenzen von Schülerinnen und Schülern im internationalen Vergleich, Opladen: Leske+Budrich, 2001.

[4] H. Burkhardt, S. Groves, A. H. Schoenfeld and K. Stacey (eds.), Problem Solving - A World View, Proceedings of Problem Solving Theme Group of the Fifth International Congress on Mathematical Education, Adelaide 1984, Shell Center for Mathematical Education, Nottingham, 1988.

[5] Judita Cofman, Einblicke in die Geschichte der Mathematik; Aufgaben und Materialien für die Sekundarstufe I, Texte zur Didaktik der Mathematik, Berlin, 1999.

[6] Judita Cofman, Einblicke in die Geschichte der Mathematik II; Aufgaben und Materialien für die Sekundarstufe II, Texte zur Didaktik der Mathematik, Spektrum Akademischer Verlag Heidelberg, Berlin, 2001.

[7] J. Cukrowicz and B. Zimmermann (eds. and coauthors), MatheNetz vols./grade 5-11; Gymnasien, Westermann Schulbuchverlag, Braunschweig, 2000-2003.

[8] William G. Durden, Collaboration with a Legacy - The Johns Hopkins University CTY - University of Hamburg Models for the Advancement of Mathematically Talented Youth, In: Zimmermann 1995 ([35]).

[9] P. A. Frensch and J. Funke (eds.), Complex Problem Solving, The European Perspective, Lawrence Erlbaum Associates, Hillsdale, 1995.

[10] Torsten Fritzlar, Überlegungen zur Sensibilität von Studierenden für die Komplexität spezifischer Aspekte problemorientierten Mathematikunterrichts, Dissertation, Friedrich-Schiller-Universität, Jena, 2003.

[11] C. J. Gerhardt (ed.), Die Philosophischen Schriften von Gottfried Wilhelm Leibniz, Vol. 7 Weidmannsche Buchhandlung, Berlin, 1890, Reprint of G. Olms, Hildesheim - New York 1978.

[12] T. L. Heath, The Thirteen Books of Euclid's Elements, Cambridge University Press, Cambridge, 1925.

[13] Frank Heinrich, Theoretische Analysen und empirische Erkundungen über das Wechseln von Lösungsanläufen beim Lösen mathematischer Probleme, Habilitationsschrift, Friedrich-Schiller-Universität, Jena, 2003. 
[14] J. P. Hogendijk, Review of Rashed 1989, Mathematical Reviews Sections, 91d:01002 01A30 01A20 11-03, S. 1822, April 1991 - Issue 91d.

[15] Jens Høyrup, Lengths, Widths, Surfaces - A Portrait of Old Babylonian Algebra and Its Kin, Springer, New York, Berlin, Heidelberg, 2002.

[16] Inter-IREM Commission, History of Mathematics - Histories of Problems, Translated by C. Weeks, Preface by J. Fauvel, Ellipses, Paris, 1997.

[17] K. Jaouiche, Ibn al Haitham: Kitab at-tahlil wa-t-tarkib, Ouvrage d'al-H,.asan ibn al al-H,.asan ibn al Haitham sur l'analyse et la synthése, Unpublished manuscript, Paris, 1991.

[18] A. Jones (ed. \& transl.), Pappus of Alexandria, Book 7 of the Collection, Part 1 + Part 2, Springer, New York, 1986.

[19] K. Kießwetter, Unterrichtsgestaltung als Problemlösen in komplexen Konstellationen - Welche Ansatzpunkte liefern die Untersuchungen des Kognitionspsychologen D. Dörner für das Verständnis der dabei auftretenden Anforderungen und Phänomene und für eine Revision der Lehrerausbildung?, Beiträge zum Lernen und Lehren von Mathematik, (F. Padberg, ed.), Kallmeyer Seelze, 1994.

[20] K. Kießwetter, Unzulänglich vermessen und vermessen unzulänglich, DMV mitteilungen, Vol. 4, 2002, 49-58.

[21] G. Pólya, Mathematics and Plausible Reasoning, (2 Vols.), University Press, Princeton, 1954.

[22] G. Pólya, How to Solve It, (2nd edn.), Doubleday, New York, 1973.

[23] G. Pólya, Mathematical Discovery (Vol. 1 and 2), Combined paperback edn., Wiley, New York, 1980.

[24] R. Rashed, Ibn al-Haytham et les nombres parfaits, Historia Mathematica 16 (1989), 343-352.

[25] Gundula Seidel, Ordnung und Multimodalität im Denken mathematisch Hochbegabter: sequentielle und topologische Eigenschaften kognitiver Mikrozustände, Dissertation, Friedrich-Schiller-Universität Jena, 2001.

[26] E. A. Silver (ed.), Teaching and Learning Mathematical Problem Solving: Multiple Research Perspectives, Lawrence Erlbaum Associates, Hillsdale, 1985.

[27] Manfred Spitzer, Lernen, Gehirnforschung und die Schule des Lebens, Spektrum Akademischer Verlag, Heidelberg, Berlin, 2002.

[28] R. Stowasser, Organizing Ideas from the History of Mathematics drawn from the History, University of Chicago School Mathematics Project, Development in School Mathematics Education around the World, NCTM, p. 494-513, Reston, 1987.

[29] D. J. Struik, A Source Book in Mathematics, 1200-1800, Princeton University Press, Princeton, 1986.

[30] O. Toeplitz, The Calculus, a Genetic Approach, University of Chicago Press, Chicago, 1963.

[31] H. Wagner and B. Zimmermann, Identification and Fostering of Mathematically Gifted Students, Educational Studies in Mathematics 17 (1986), 243-259. 
[32] B. Zimmermann, Interim Report on a Project to Identify and Foster Mathematically Gifted Students, In: Burkhardt/Groves/Schoenfeld/Stacey, 1988.

[33] B. Zimmermann, Heuristische Strategien in der Geschichte der Mathematik, In: Finden, Erfinden, Lernen. Zum Umgang mit Mathematik unter heuristischem Aspekt, (M. Glatfeld, ed.), Frankfurt a. M: Peter Lang., 1990.

[34] B. Zimmermann, Heuristik als ein Element mathematischer Denk- und Lernprozesse, Fallstudien zur Stellung mathematischer Heuristik im Bild von Mathematik bei Lehrern und Schülern sowie in der Geschichte der Mathematik, Habilitation, Universität Hamburg, Hamburg, 1991.

[35] B. Zimmermann (ed.), Kaleidoskop elementarmathematischen Entdeckens, Franzbecker, Hildesheim, 1995.

[36] B. Zimmermann, Problem orientation as a leading Idea in Mathematics Instruction, In: Memorias del VI Simposio Internacional en Educación Matemática Elfriede Wenzelburger, 13 al 15 Octubre, 1997, Ciudad de México, México, Conferencia Magistrale, 11-21.

[37] B. Zimmermann, On a Study of Teacher Conception of Mathematics Instruction and some Relations to TIMSS, In: Current State of Research on Mathematical Beliefs, Proceedings of the MAVI-Workshop University of Duisburg, April 11-14, 1997a, (Törner, G., ed.).

[38] B. Zimmermann, On Changing Patterns in the History of Mathematical Beliefs, In: Current State of Research on Mathematical Beliefs VI, Proceedings of the MAVI-Workshop University of Duisburg, (Törner, G., ed.), März 6-9, 1998, $107-117$.

[39] B. Zimmermann, On some Issues on Mathematical Problem Solving from an European Perspective, Problem Solving Around the World, Proceedings of the Topic Study Group 11 (Problem Solving in mathematics Education) at the ICME-9 meeting August 2000 in Japan, University of Turku, Faculty of Education, Department of Teacher Education, Report Series C:14, Turku, (Pehkonen, ed.), 2001, $55-64$.

[40] B. Zimmermann, On the Genesis of Mathematics and Mathematical Thinking a Network of Motives and Activities drawn from History of Mathematics, From over - conceptualisation towards meaningful mathematics and science education, Proceedings on the Annual Symposium of the Finnish Mathematics and Science Education Research, (L. Haapasalo \& K. Sormunen, eds.), University of Joensuu, 2003, 29-47.

BERND ZIMMERMANN

UNIVERSITY OF JENA

GERMANY

E-mail: bezi@minet.uni-jena.de

(Received September, 2003) 